NOTAS 



\title{
LA PLATAFORMA EUROPEA DE RESOLUCIÓN DE LITIGIOS EN LÍNEA (ODR) \\ EN MATERIA DE CONSUMO
}

\author{
FÉLIX VALBUENA GONZÁLEZ'
}

\begin{abstract}
Revista de Derecho Comunitario Europeo ISSN-L 1138-4026, núm. 52, Madrid, septiembre/diciembre (2015), pp. 987-1016 http://dx.doi.org/10.18042/cepc/rdce.52.05

Cómo citar/Citation

Valbuena González, F. (2015). La plataforma europea de resolución de litigios en línea (ODR) en materia de consumo, Revista de Derecho Comunitario Europeo, 52, 987-1016. doi: http://dx.doi.org/10.18042/cepc/rdce.52.05
\end{abstract}

\section{Resumen}

El presente artículo se propone realizar un estudio acerca de la plataforma europea de resolución de litigios en línea en materia de consumo, ante su inminente puesta en funcionamiento, prevista para el 9 de enero de 2016. A tal efecto, se examinan inicialmente los antecedentes y caracteres principales; acto seguido, se aborda su ámbito de aplicación así como la tramitación en línea del procedimiento; finalmente, se exponen las conclusiones extraídas del análisis previo.

\section{Palabras clave}

Unión Europea; resolución de litigios en línea; consumidor; comerciante; entidad de resolución alternativa; comercio electrónico.

1 Profesor contratado doctor de Derecho Procesal. Universidad de Burgos. Magistrado suplente en la Audiencia Provincial de Burgos.

El presente trabajo se enmarca dentro del proyecto de investigación titulado «Aproximación legislativa versus reconocimiento mutuo en el desarrollo del Espacio Judicial Europeo: una perspectiva multidisciplinar» (DER2012-35862), financiado por el Ministerio de Ciencia y Competitividad para el trienio 2013-2015, cuya investigadora principal es la profesora Mar Jimeno Bulnes. 


\section{EUROPEAN ODR PLATFORM FOR CONSUMERS AND TRADERS}

\section{Abstract}

This paper proposes an analysis of the European ODR platform for consumers and traders that should be operative the 9th January 2016. In this context, it will be examine first its background and main principles; second, its scope and the online procedure; third and finally, a sort of concluding remarks shall be exposed.

Key words

European Union; ODR; consumer; trader; ADR entity; e-commerce.

\section{LA PLATEFORME EUROPÉENNE POUR LA RESOLUTION DES LITIGES EN LIGNE (RLL) ENTRE CONSOMMATEURS ET PROFESSIONNELS}

\section{Résumé}

Cet article propose une étude sur la plateforme européenne pour la résolution des litiges en ligne (RLL) entre consommateurs et professionnels, avant sa mise en service imminente, prévue pour le 9 Janvier 2016. Dans ce contexte, on examine d'abord son contexte et les principes principaux; deuxième, sa portée et la procédure en ligne; troisième et enfin, une sorte de conclusion doit être exposé.

\section{Mots clés}

Union européenne; résolution de litiges en ligne (RLL); consommateurs; commerçants; entité de règlement extrajudiciaire des litiges (REL); commerce électronique. 


\section{SUMARIO}

I. INTRODUCCIÓN. II. ANTECEDENTES. III. CARACTERES PRINCIPALES: 1. Instituciones implicadas 2. Configuración técnica y funcionalidad. IV. ÁMBITO DE APLICACIÓN. V. TRAMITACIÓN EN LÍNEA DEL PROCEDIMIENTO: 1. Presentación de la reclamación 2. Determinación de la entidad de resolución competente. 3. Resolución del litigio. VI. REFLEXIÓN FINAL.

\section{INTRODUCCIÓN}

El Parlamento Europeo y el Consejo adoptaron, el 21 de mayo de 2013, el Reglamento (UE) 524/2013 del Parlamento Europeo y del Consejo, sobre resolución de litigios en línea en materia de consumo ${ }^{2}$. Como instrumento normativo europeo de alcance general y efecto directo, resulta aplicable a partir del 9 de enero de 2016 (art. 22.2), esto es, dos años y medio después de su entrada en vigor, que se produjo el 8 de julio de 2013.

Coetáneamente se publica la Directiva 2013/11/UE relativa a la resolución alternativa de litigios en materia de consumo ${ }^{3}$, que también presenta carácter vinculante pero carece — no obstante- de efecto directo, precisando de la correspondiente transposición a los ordenamientos jurídicos de los Estados miembros, antes del 9 de julio de 2015 (art. 25).

Ambos instrumentos legislativos aparecen indisociablemente relacionados, puesto que el Reglamento pone a disposición de las entidades alternativas en materia de consumo que cumplan con los principios de la Directiva, una plataforma europea de resolución de litigios en línea, que constituye el objeto de atención primordial en este trabajo.

2 DOUE de 18 de junio de 2013, núm. L 165, pp. 1-12.

3 Sobre la misma, puede verse nuestro anterior trabajo: Félix VALBUENA GONZÁLEZ, «La directiva europea sobre resolución alternativa de litigios (ADR) en materia de consumo", Justicia. Revista de Derecho Procesal, núm. 2, 2014, pp. 409-443; asimismo, Aura Esther VILALTA NICUESA, «La paradoja de la mediación en línea. Recientes iniciativas de la Unión Europea y de la CNUDMI», Revista General de Derecho Europeo, núm. 33, 2014, pp. 1-35 (Revistas@iustel. com), esp. pp. 10-16. 
La plataforma electrónica se concibe no solo como instrumento al servicio de las entidades de resolución de litigios, que se registrarán obligatoriamente en la misma, sino como ventanilla única para los consumidores y comerciantes que deseen resolver extrajudicialmente los litigios dentro del ámbito de aplicación del citado Reglamento.

De hecho, la garantía de un elevado nivel de protección de los consumidores en la Unión Europea se erige como primer elemento justificativo de su creación, de acuerdo con lo previsto en el Tratado de Funcionamiento (arts. 169.1 y 169.2.a) y la Carta de Derechos Fundamentales de la Unión Europea (art. 38).

Junto a este carácter tuitivo para el consumidor, un segundo elemento justificativo de esta iniciativa — no menos importante — vendría representado por la necesidad de asegurar el buen funcionamiento del mercado interior europeo, concebido como un espacio sin fronteras, en el que está garantizada la libre circulación de bienes y servicios ${ }^{4}$.

Se protege, específicamente, la dimensión digital del mercado interior, habida cuenta del auge que progresivamente está adquiriendo el denominado comercio electrónico (e-commerce), puesto que cada vez un mayor número de consumidores y comerciantes compran y venden, respectivamente, en línea ${ }^{5}$.

Así, la confianza de los consumidores en el comercio electrónico se potencia al poner a su disposición un sistema ODR de resolución de conflictos ${ }^{6}$, particularmente indicado para los denominados litigios transfronterizos - esto es, cuando comerciante y consumidor se encuentran ubicados en distintos Estados — , sin excluir tampoco la resolución de los litigios do-

\section{Art. 26.2 TFUE.}

5 Solo en España, la facturación total del comercio electrónico ha alcanzado los 4.102,8 millones de euros en el tercer trimestre de 2014, un 24,7\% más que en el mismo periodo del año anterior. La contratación de paquetes turísticos, hoteles y viajes acapara la tercera parte del negocio (el 34,2\% del total) que realizan los españoles a través de Internet, aunque por número de transacciones la compra de discos, libros y periódicos ocupa el primer lugar, según el Informe de la comisión nacional de los Mercados y la Competencia correspondiente al tercer trimestre de 2014, disponible en http://data.cnmc.es/datagraph/ (consultado por última vez el 19 de mayo de 2015).

6 Una de las primeras definiciones de ODR se debe a Ethan KASTH y Janet RIFKIN, Online Dispute Resolution. Resolving Conflicts in Cyberspace, Jossey-Bass, San Francisco, 2001, esp. pp. 93-116, quienes sostienen que los ODR facilitan la resolución de conflictos a través del poder transformador de la tecnología (TIC), que se incorpora como cuarta parte al modelo tripartito tradicional, integrado por solicitante, requerido y operador del conflicto.

7 La divergencia entre las legislaciones nacionales, los problemas lingüísticos o la distancia geográfica entre los interesados son elementos que disuaden a la hora de 
mésticos. La tramitación en línea del procedimiento incrementa el grado de simplicidad y rapidez que tradicionalmente ya ofrecen las técnicas de $\mathrm{ADR}^{8}$.

\section{ANTECEDENTES}

La creación de una plataforma de resolución de litigios en línea (ODR) en materia de consumo se enmarca dentro de la Política sectorial europea de protección de los consumidores, si bien aparece relacionada asimismo con el interés creciente ${ }^{9}$ en la Unión Europea por los métodos alternativos de resolución de conflictos (ADR) —en especial de la mediación—, dentro del contexto de las políticas de mejora en el acceso a la justicia.

El hito más destacado en esta materia viene constituido, sin duda, por la publicación de la Directiva 2008/52/CE, del Parlamento europeo y del Consejo de 21 de mayo de 2008, sobre ciertos aspectos de la mediación en asuntos civiles y mercantiles ${ }^{10}$, que regula por vez primera, a nivel comunitario, un sistema de solución de conflictos que prescinde de la intervención judicial ${ }^{11}$.

hacer valer los derechos en un país extranjero. En este sentido, Manuel RICHARD GONZÁLEZ, «Los procedimientos electrónicos de resolución alternativa de conflictos (on-line dispute resolution)», Diario La Ley, núm. 8360, 23 de julio de 2014, pp. 1-14, esp. p. 6.

Entre ADR (Alternative Dispute Resolution) y ODR la diferencia estriba en el medio usado para poner en contacto a los sujetos en conflicto, de manera que cuando entra en juego un medio de comunicación a distancia, la controversia puede resolverse en línea y, por ende, la resolución de la controversia toma el nombre de On Line Dispute Resolution. Véase Lucia RUGGERI, "ADR y ODR y su taxonomía. La identificación de caracteres", en Justicia relacional y métodos electrónicos de resolución (ODR): hacia una armonización técnica y legal [monográfico en línea]. IDP. Revista de Internet, Derecho y Política, núm. 10, 2010, pp. 32-39, esp. p. 36, disponible en la dirección: http://idp.uoc.edu/ojs/index.php/ idp/article/view/n10-ruggeri/n10-ruggeri (consultado por última vez el 28 de julio de 2014).

9 Un examen de la normativa comunitaria muestra el nacimiento, en los últimos veinte años, de una tendencia a seguir las formas de resolución de las controversias alternativas a los remedios jurisdiccionales. En este sentido, Lucia RUGGERI, "ADR y ODR y su taxonomía. La identificación de caracteres», op. cit., esp. p. 33. DOUE de 25 de abril de 2008, núm. L 136, pp. 3-8.

11 Sobre el particular, más ampliamente, puede verse nuestro anterior trabajo: Félix VALBUENA GONZÁLEZ, "Instrumentos procesales civiles. Mediación», en Mar JIMENO BULNES (coord.), Nuevas aportaciones al Espacio de Libertad, Seguridad y Justicia: hacia un derecho procesal europeo de naturaleza civil y penal, Comares, Granada, 2014, pp. 123-151. Asimismo, Juan Carlos ORTIZ PRA- 
Por su parte, el origen de la Política sectorial europea de protección de los consumidores se remonta a 1992 con el Tratado de Maastricht, que introduce dos menciones expresas en el Tratado de la Unión Europea ${ }^{12}$, si bien ya con anterioridad el Acta Única Europea de 1986 contenía una primera alusión a la misma ${ }^{13}$.

Con posterioridad, la acción comunitaria sobre Política de los consumidores se ha desarrollado mediante sucesivos planes trienales, con distintos ámbitos de actuación ${ }^{14}$. En concreto, la adopción del Reglamento sobre resolución alternativa de litigios en línea en materia de consumo se produce en el marco del Programa de protección de los consumidores aprobado en diciembre de 2006 por la Unión Europea, en este caso para seis años (2007-2013), que aparece dotado con un presupuesto total de 157 millones de euros.

Este nuevo Programa ${ }^{15}$ presenta dos grandes objetivos: de un lado, dotar a los consumidores de un alto nivel de protección gracias a una mejor infor-

DILLO, «La mediación en la Unión Europea: la Directiva sobre ciertos aspectos de la mediación en asuntos civiles y mercantiles», en Nicolás GONZÁLEZ CUÉLLAR SERRANO (coord.), Mediación: un método de resolución de conflictos: estudio interdisciplinar, pp. 55-72

12 De una parte el art. 3 TUE establece que la acción de la Comunidad implicará una contribución al fortalecimiento de la protección de los consumidores y, de otro lado, el art. 129 A señala que tal objetivo debe perseguirse a través de medidas y acciones concretas que apoyen y complementen la política llevada a cabo por los Estados miembros. A juicio de algunos autores, este último precepto supuso una decisiva aportación a la implantación de la política europea de protección de los consumidores, puesto que -además de reiterar la mención al objetivo del alto nivel de protección (Acta Única Europea) — añade los instrumentos jurídicos para alcanzarlo, con una clara legitimación de medidas no estrictamente dependientes de la consecución del mercado interior, si bien se trata de un precepto confuso que presenta problemas de interpretación. En este sentido, Gemma BOTANA GARCÍA y Miguel RUIZ MUÑOZ (coords.), Curso de protección jurídica de los consumidores, Editorial McGraw-Hill Interamericana de España, Madrid, 1999, esp. pp. 14-21.

13 Concretamente, el art. 100 A.3 señala: «La Comisión, en sus propuestas previstas en el art. 1 referente a la aproximación de las legislaciones en materia de salud, seguridad, protección del medio ambiente y protección de los consumidores, se basará en un nivel de protección adecuado».

14 Así, por ejemplo, a lo largo de los últimos años se han ido introduciendo medidas que protegen los intereses generales del consumidor en ámbitos como los siguientes: prácticas empresariales leales, publicidad engañosa y comparativa, indicadores y etiquetado de precios, cláusulas contractuales abusivas, venta a distancia y a domicilio, multipropiedad y vacaciones combinadas, derechos de los viajeros.

15 Programa de acción comunitaria en el ámbito de la política de los consumidores (2007-2013), aprobado por Decisión 1926/2006/CE del Parlamento Europeo y del 
mación, consulta y representación de sus intereses y, de otro lado, conseguir la aplicación efectiva de la normativa de protección de los consumidores mejorando la cooperación, la información, la educación y las vías de recurso.

No obstante, conviene remontarse a los orígenes de la Política sectorial de protección de los consumidores para observar la trayectoria seguida hasta el momento actual, en que se procede a la creación de una plataforma europea para la solución on line de litigios derivados de relaciones de consumo ${ }^{16}$.

Coincidiendo prácticamente en el tiempo con la entrada en vigor del Tratado de Maastricht, la Comisión presenta en 1993 el Libro Verde sobre acceso a la justicia y solución de litigios en materia de consumo en el mercado interior $^{17}$.

Este documento previo a la presentación de propuestas formales examina la situación en los diferentes Estados miembros y esboza una serie de orientaciones e iniciativas, abriendo la puerta a un debate sobre los diversos asuntos planteados. Objeto de una amplia consulta, evidenció la necesidad de una iniciativa en favor de procedimientos rápidos, eficaces y de bajo coste; que garantizasen una adecuada tutela de los ciudadanos europeos ${ }^{18}$.

Tal acción comunitaria se concreta inicialmente —años después — en sendas Recomendaciones, de carácter no vinculante, referidas a los principios aplicables a los órganos responsables de la solución extrajudicial de los litigios en materia de consumo. De un lado, la Recomendación 1998/257/CE, de 30 de marzo $^{19}$, relativa a los órganos heterocompositivos (arbitraje) y, de otro

Consejo, de 18 de diciembre de 2006. Versión digital disponible en <http://eur-lex. europa.eu/smartapi/cgi/sga_doc?smartapi!celexplus!prod!DocNumber\&lg=es\&type_doc=Decision\&an_doc=2006\&nu_doc=1926> (consultado por última vez el 13 de marzo de 2015).

16 Una iniciativa en esta materia estaba siendo reclamada desde hace tiempo por la doctrina científica. Véase, por todos, Pablo CORTÉS, Online dispute resolution for consumers in the European Union, Routledge, Oxon, 2011, esp. pp. 181-207, con la correspondiente propuesta de lege ferenda.

17 Documento COM (93) 576 final, de 16 de noviembre de 1993.

18 Más ampliamente: Juan Manuel BADENAS CARPIO, «Los litigios fronterizos: notas al Libro Verde sobre el acceso de los consumidores a la justicia y solución de litigios de consumo en el mercado único europeo», Estudios sobre Consumo, núm. 29, 1994, pp. 25-37; asimismo, Juan Manuel MARTÍN BERNAL, «El arbitraje como defensa de los consumidores y usuarios en España y en el Derecho Comunitario», Estudios sobre Consumo, núm. 45, 1998, pp. 67-86, esp. pp. 70-82.

19 Publicada en el DOCE de 17 de abril de 1998, núm. L 115, aparece acompañada de una Comunicación de la Comisión no publicada en el Diario Oficial [Documento COM (1998), 198 final]. 
lado, la Recomendación 2001/310/CE, de 4 de abril20 ${ }^{20}$ dedicada a los órganos autocompositivos (mediación y conciliación).

La Unión Europea se muestra, así, consciente de las tradicionales dificultades de acceso de los consumidores a la justicia, derivadas de la duración y coste del procedimiento judicial, frente al limitado valor económico de la reclamación efectuada, razón por la cual numerosos particulares renuncian a hacer valer sus derechos ante los tribunales.

En efecto, en el ámbito de las relaciones de consumo se producen mayoritariamente reclamaciones de pequeña cuantía, cuya resolución puede conseguirse a través de procedimientos ágiles, desprovistos de formalidades y gratuitos, para facilitar su acceso por los particulares afectados ${ }^{21}$.

Por esta razón, no solo la Unión Europea sino otros poderes públicos ${ }^{22}$ vienen fomentando, desde hace tiempo, el establecimiento de vías alternativas a la judicial (ADR) para la resolución de las controversias derivadas del consumo, como una opción de política legislativa.

20 Publicada en el DOCE de 19 de abril de 2001, núm. L 109, se acompaña también de una Comunicación no publicada oficialmente [Documento COM (2001), 161 final].

21 Ya tuvimos ocasión de destacarlo en uno de nuestros primeros trabajos sobre arbitraje. Véase Félix VALBUENA GONZÁLEZ, «Aproximación al sistema arbitral de consumo", Jurisoft-Revista jurisprudencial de los Ilustres Colegios de Abogados de Ávila, Burgos y Cantabria, época II, núm. 6, mayo 1998, pp. 7-10, esp. p. 10.

22 Resulta conocido cómo en nuestro Estado la opción elegida ha sido tradicionalmente la vía arbitral, ya desde la derogada Ley 20/1984, de 19 de julio, General para la Defensa de los Consumidores y Usuarios, cuyo art. 31 instaba a que el Gobierno estableciera un sistema arbitral para la resolución de los conflictos en materia de consumo. Con base exclusivamente en este precepto, comenzó a desarrollarse - a partir de mayo de 1986 - una experiencia piloto, con el propósito de conocer el grado de aceptación del sistema por consumidores y empresarios, así como las necesidades reales para su funcionamiento. El respaldo ofrecido por las asociaciones de consumidores, unido a los resultados que se produjeron, condujo a una positiva valoración de la experiencia y a la necesidad — con el fin de extenderla al resto del Estado- de elaborar una primera reglamentación específica, lo que se produjo mediante el Real Decreto 636/1993, de 3 de mayo, regulador del Sistema Arbitral de Consumo, al que sucedió el vigente Real Decreto 231/2008, de 15 de febrero. Sobre el particular, puede verse, entre otros: Manuel Jesús MARÍN LÓPEZ, «La nueva regulación del arbitraje de consumo: el Real Decreto 231/2008, de 15 de febrero», Diario La Ley, núm. 6905, 2008; Raquel BONACHERA VILLEGAS, «El Real Decreto 231/2008, la anhelada modificación del sistema arbitral de consumo», Diario La Ley, núm. 7045, 2008; Antonio María LORCA NAVARRETE, La nueva regulación del arbitraje de consumo, Instituto Vasco de Derecho Procesal, San Sebastián, 2008. 
Recientemente, la Directiva 2013/11/UE, relativa a la resolución alternativa de litigios en materia de consumo ${ }^{23}$, ha supuesto un nuevo avance en la protección de los consumidores dentro de la Unión Europea, siguiendo la línea trazada por las anteriores Recomendaciones de 1998 y 2001.

Dicho instrumento procede a la creación de una categoría legal nueva, conocida como "entidad de resolución alternativa», reservada para aquella que cumpla con los requisitos previstos en el mismo; que son objeto de evaluación y control por las autoridades competentes de cara a su inclusión en una lista pública, cuya primera versión debe estar disponible antes del 9 de enero de 2016, coincidiendo con la fecha en que debe encontrarse operativa la plataforma.

Las exigencias impuestas por la Directiva no difieren sustancialmente de los principios sugeridos en las precedentes Recomendaciones, salvo por su carácter ahora vinculante. Consisten esencialmente en: accesibilidad y transparencia de las propias entidades de resolución alternativa; imparcialidad y conocimientos especializados para los sujetos encargados de la solución del litigio; eficacia, libertad y equidad como principios rectores de los procedimientos empleados para resolver el conflicto.

La transposición de la Directiva a los ordenamientos de los Estados miembros ha exigido, en algunos supuestos, la adopción de la consiguiente normativa interna ${ }^{24}$. En el caso de España, contamos con un Anteproyecto de Ley de Resolución Alternativa de Conflictos de Consumo ${ }^{25}$, pendiente aún del trámite parlamentario antes de su aprobación definitiva.

23 En adelante, Directiva ADR.

24 Así, por ejemplo, en Bélgica la «Loi du 4 avril 2014 portant insertion du Livre XVI, "Règlement extrajudiciaire des litiges de consommation" dans le Code de droit économique» (Moniteur Belge, de 12 de mayo de 2014); en Francia, la "Ordonnance núm. 2015-1033 du 20 aồt 2015 relative au règlement extrajudiciaire des litiges de consommation" (JORF, de 21 de agosto de 2015); o en Reino Unido, "The alternative dispute resolution for consumer disputes (amendment) regulations 2015» (HMSO, de 18 de junio de 2015), entre otras. Un listado actualizado de las medidas nacionales de adaptación de la Directiva que van siendo comunicadas a la Comisión desde su entrada en vigor puede consultarse en: eur-lex.europa.eu/ legal-content/ES/NIM/?uri=CELEX:32013L0011 (consultado por última vez el 30 de septiembre de 2015).

25 En adelante, Anteproyecto Ley RACC. El texto sometido a fase de consulta aparece publicado, con fecha 16 de abril de 2015, en el portal de la transparencia del Gobierno de España - transparencia.gob.es- (consultado por última vez el 30 de septiembre de 2015). Sobre el mismo, más ampliamente, puede verse Lourdes GARCÍA MONTORO, “Nuevo” modelo de resolución alternativa de conflictos de consumo a la luz del anteproyecto de ley de resolución alternativa 
Finalmente, la creación de la plataforma europea, a través del Reglamento (UE) 524/2013, de 21 de mayo, sobre resolución de litigios en línea en materia de consumo ${ }^{26}$, dota a estas entidades de resolución alternativa del instrumento que posibilita la tramitación de litigios en línea en materia de consumo, lo que constituye una novedad sin precedentes ${ }^{27}$.

Se puede decir para finalizar este apartado de antecedentes que el camino seguido hasta el presente ha transcurrido por dos fases bien diferenciadas: en un primer momento, la de creación y consolidación de estructuras de ADR para la solución de los litigios de consumo, inicialmente a través de normas con carácter no vinculante (Recomendaciones) y, posteriormente, mediante un instrumento de obligada transposición (Directiva) por parte de los Estados miembros ${ }^{28}$.

de conflictos de consumo. Especial referencia a las posibilidades de supervivencia de la mediación y otros mecanismos tradicionales», Revista CESCO de Derecho de Consumo, núm. 14, 2015, pp. 11-27. Reviste gran interés también el Informe al Proyecto adoptado por el Consejo General del Poder Judicial con fecha 11 de junio de 2015, disponible en www.poderjudicial.es. (consultado por última vez el 30 de septiembre de 2015).

En lo sucesivo, Reglamento ODR.

En el ámbito de la Comisión de las Naciones Unidas para el Derecho Mercantil Internacional (CNUDMI/UNCITRAL) se trabaja, no obstante, en una iniciativa semejante, que se presenta como ley modelo y es conocida como proyecto de Reglamento sobre la solución de controversias por vía informática en las operaciones transfronterizas de comercio electrónico. Más ampliamente, véase Manuel RICHARD GONZÁLEZ, «Los procedimientos electrónicos de resolución alternativa de conflictos (on-line dispute resolution)», op. cit., esp. pp. 9-14; asimismo, Aura Esther VILALTA NICUESA, «La paradoja de la mediación en línea. Recientes iniciativas de la Unión Europea y de la CNUDMI", op. cit., esp. pp. 18-31.

La situación preexistente en los Estados miembros se muestra en el estudio comparativo realizado por Cristopher HODGES, Iris BENÖHR y Naomi CREUTZFELDT-BANDA, Consumer ADR in Europe. Civil Justice Systems, Hart Publishing, Oxford, 2012, donde se describen los sistemas de resolución extrajudicial de conflictos en materia de consumo, vigentes en países como Bélgica, Francia, Alemania, Holanda o España, entre otros, apreciando la diversidad de fórmulas adoptadas. A título de ejemplo cabe citar el protocolo «Belmed» en Bélgica, una aplicación online para arbitraje, conciliación y mediación; los mediadores en consumo («mediateurs») en Francia, de larga tradición; el sistema creado por las Cámaras de Comercio («Wettbewerbszentrale») en Alemania, con un número elevado de casos resueltos anualmente, en un gran porcentaje a través de la conciliación; o el modelo estandarizado de las «Geschillencomissie» en Holanda, aplicable a todos los sectores del consumo excepto al financiero. 
En un segundo momento, alcanzado el objetivo de contar con entidades de resolución de litigios con unos niveles de calidad armonizados en toda la Unión Europea, se habilita un sistema ODR mediante la creación de la plataforma europea, a través de un acto de alcance general y efecto directo (Reglamento).

\section{CARACTERES PRINCIPALES}

Seguidamente examinamos las principales características de la plataforma, pero antes de abordar su configuración tanto desde el punto de vista técnico como funcional, nos detenemos en distinguir las instituciones que asumen algún tipo de responsabilidad en su puesta en marcha y posterior gestión.

\section{INSTITUCIONES IMPLICADAS}

La Comisión aparece como responsable, en primer lugar, del desarrollo y establecimiento de la plataforma y, posteriormente, de su funcionamiento ${ }^{29}$, incluidos los aspectos relativos a traducción, mantenimiento, financiación y seguridad de los datos ${ }^{30}$.

En dicha tarea, la Comisión se encuentra asistida por un comité ${ }^{31}$, compuesto por representantes de los Estados miembros y presidido por un representante de la Comisión, que no participa en las votaciones ${ }^{32}$. El comité actúa de acuerdo con las normas y principios generales que regulan los mecanismos aplicables en los casos en que un acto jurídicamente vinculante de la Unión (como es el Reglamento) determine la necesidad de condiciones uniformes de ejecución y requiera que la adopción de actos de ejecución ${ }^{33}$ por la Comisión esté sometida al control de los Estados miembros.

Este último aspecto, relativo al almacenamiento, tratamiento y confidencialidad de los datos personales, así como el acceso a la información relacionada con el litigio, es objeto de especial atención en el Reglamento ODR (arts. 11-13), que lamentablemente - a pesar de su indudable interés - no podemos abordar por falta de espacio.

\section{Art. 16.1 Reglamento ODR.}

Art. 3.2 del Reglamento (UE) 182/2011, del Parlamento Europeo y del Consejo, de 16 de febrero de 2011, por el que se establecen las normas y los principios generales relativos a las modalidades de control por parte de los Estados miembros del ejercicio de las competencias de ejecución por la Comisión (DOUE núm. L 55, de 28 de febrero de 2011, pp. 13-20)

Concretamente, está previsto que se emplee el procedimiento consultivo (art. 4 del Reglamento (UE) núm. 182/2011) para la adopción de actos de ejecución relativos 
En este ámbito, la Comisión ha adoptado recientemente ${ }^{34}$ el Reglamento de ejecución (UE) 2015/1051, de 1 de julio, sobre las modalidades para el ejercicio de las funciones de la plataforma de litigios en línea, sobre las modalidades de impreso electrónico de reclamación y sobre las modalidades de cooperación entre los puntos de contacto previstos en el Reglamento ODR, cuya entrada en vigor está prevista a los veinte días de su publicación oficial, esto es, el 23 de julio de 2015.

$\mathrm{Al}$ margen de las funciones de asistencia en la gestión, las labores de apoyo en relación con las reclamaciones presentadas a través de la plataforma, se prestan por los puntos de contacto de resolución de litigios en línea ${ }^{35}$.

A tal efecto, cada Estado miembro designa un punto de contacto que comunica a la Comisión (nombre y datos de contacto), pudiendo conferir esta responsabilidad a los centros de la Red de Centros Europeos del Consumidor $^{36}$, pero también a las asociaciones de consumidores o a cualquier otro organismo, siempre con la condición de que cada punto de contacto incorpore al menos dos asesores en resolución de litigios en línea ${ }^{37}$.

al formulario electrónico de reclamación, por su carácter puramente técnico. Sin embargo, debe utilizarse el procedimiento de examen (art. 5 del Reglamento (UE) 182/2011) para la adopción de las normas relativas a las modalidades de cooperación entre los asesores de resolución de litigios de la red de puntos de contacto de resolución de litigios en línea.

DOUE núm. L 171, de 2 de julio de 2015, pp. 1-4.

Art. 7 Reglamento ODR.

La Red de Centros Europeos de los Consumidores (Red CEC) resulta de la fusión en 2005 de dos redes preexistentes, ambas con funciones de protección de los consumidores: de un lado, la Red de órganos responsables de la solución extrajudicial de litigios en materia de consumo (Red EJE) y, de otro lado, la Red de Euroventanillas. Aparece estructurada a través de puntos de contacto nacionales, disponiendo todos los Estados miembros al menos de un centro de intercambio de información (en España es el Instituto Nacional de Consumo), que ofrece asesoramiento a consumidores y usuarios, de especial utilidad en conflictos surgidos con proveedores de otros países de la Unión Europea (litigios transfronterizos). Sus objetivos se centran no solo en facilitar información a fin de que los consumidores puedan adquirir bienes y disfrutar de servicios con pleno conocimiento de sus derechos y deberes, sino también en prestar apoyo con motivo de un conflicto, facilitando a los consumidores el acceso a una vía de compensación. Más ampliamente: Ana MONTESINOS GARCÍA, «Los retos del arbitraje ante las nuevas tecnologías», en Silvia BARONA VILAR, Arbitraje y Justicia en el siglo XXI, Aranzadi, Pamplona, 2007, pp. 237-268. En el caso de España el punto de contacto de resolución de litigios en línea (ODR) no se ha designado todavía. Sin embargo, en materia de ADR, se proyecta como punto de contacto único la Presidencia de la Agencia Española de Consumo, Segu- 
La labor encomendada se traduce, esencialmente, en el desempeño de sendas funciones: de un lado, facilitar — previa solicitud — la comunicación entre las partes y la entidad de resolución alternativa competente y, de otro lado, presentar cada dos años un informe de actividad basado en la experiencia práctica obtenida.

El apoyo prestado por los puntos de contacto deviene obligado a instancia del interesado en el supuesto de litigios transfronterizos, esto es, cuando las partes (consumidor y comerciante) tengan su residencia habitual en distinto Estado miembro, resultando facultativo para los litigios internos, salvo que los Estados decidan imponer la obligación también en estos casos.

Se prevé, finalmente, la creación por parte de la Comisión de una «red de puntos de contacto de resolución de litigios en línea» que permita su cooperación mutua ${ }^{38}$, así como la convocatoria de —al menos- dos reuniones anuales de sus miembros para el intercambio de buenas prácticas y debate de problemas recurrentes encontrados durante la utilización de la plataforma.

Si la puesta en marcha y funcionamiento de la plataforma corresponde a la Comisión y el apoyo en la tramitación de las reclamaciones a los puntos de contacto, en la tarea de sensibilización e información ${ }^{39}$ a los consumidores sobre la existencia de la plataforma se involucra, principalmente, a los Estados miembros, pero también a los propios comerciantes y a los denominados mercados en línea.

Los Estados Miembros cumplen con su cometido, bien velando o, simplemente, animando a que se proporcione un enlace electrónico a la plataforma de resolución de litigios. En el primer caso, se encuentran las entidades de resolución alternativa, los centros de la Red de Centros Europeos del Consumidor, así como las autoridades nacionales competentes para la evaluación de las entidades de resolución; en el segundo supuesto, las asociaciones de consumidores y empresariales, que no se encuentran estrictamente obligadas a ofrecerlo.

ridad Alimentaria y Nutrición (art. 27.4 Anteproyecto Ley RACC), que también aparece como autoridad competente para la acreditación de entidades de resolución alternativa (art. 27.1 Anteproyecto Ley RACC).

Al estilo de otras redes europeas de similares características, como la propia Red CEC de Centros Europeos de Consumidores, la Red FIN-NET de solución extrajudicial de conflictos limitada al sector de los servicios financieros o, inclusive, la Red judicial europea en materia civil y mercantil, creada por Decisión 2001/470/ CE del Consejo, de 21 de mayo de 2001 (DOCE de 27 de junio de 2001, núm. L 174, pp. 25-31); sobre esta última, puede verse Ángel GALGO PECO, «La Red Judicial Europea», Estudios de Derecho Judicial, núm. 28, 2000, pp. 445-461.

Art. 14 Reglamento ODR. 
Por su parte, los mercados en línea establecidos en la Unión, entendidos como prestadores de servicios de la información que permiten a los consumidores y comerciantes celebrar contratos en línea ${ }^{40}$, están obligados a ofrecer en sus propios sitios de Internet el correspondiente enlace electrónico a la plataforma de resolución de litigios en línea.

Dicha obligación también incumbe, por último, a los propios comerciantes que hagan uso del comercio electrónico. Si además se han comprometido o están obligados a recurrir a una o varias entidades de resolución alternativa de litigios en línea, deben facilitar esa información en las condiciones generales aplicables al contrato e, incluso, en el texto del mensaje, si la oferta se realiza a través de correo electrónico.

En el caso de España, el Anteproyecto Ley RACC (arts. 35 y 36) incorpora una nueva obligación de información específica relativa a las entidades de resolución alternativa, que afecta a todos los empresarios y cuya vulneración se tipifica como infracción sancionable, dejando sin efecto la prevista actualmente en el art. 21.3 y 4 LGDCU. En esencia, el nuevo régimen consiste en que el comerciante está obligado a informar de la entidad de resolución alternativa a la que se encuentra sometido con carácter general o esté dispuesto a someterse para un caso concreto, cuando el consumidor presenta una reclamación. $\mathrm{El}$ incumplimiento por los empresarios de tales obligaciones de información tendrá la consideración de infracción grave en materia de defensa de los consumidores y usuarios.

Toda esta labor de fomento acerca de la plataforma de resolución de litigios se orienta a la protección del consumidor, con la finalidad de que conozca la existencia de esta vía alternativa de reclamación, sin perjuicio de quedar preservado el derecho de las partes de acceso al sistema judicial ${ }^{41}$.

\section{CONFIGURACIÓN TÉCNICA Y FUNCIONALIDAD}

Desde un punto de vista técnico, la plataforma aparece configurada como un sitio de Internet, entendido como el espacio digital que se identifica

\footnotetext{
$40 \quad$ Art. $4.1 \mathrm{~g}$ ) Reglamento ODR.

41 El derecho a la tutela judicial efectiva aparece garantizado, actualmente, en el art. 47 de la Carta de Derechos Fundamentales de la Unión Europea. Esta Carta recoge, en un único texto por primera vez en la historia de la Unión Europea, el conjunto de los derechos civiles, políticos, económicos y sociales de los ciudadanos europeos y de todas las personas que viven en el territorio de la Unión, agrupados en seis grandes capítulos, a saber: dignidad, libertad, igualdad, solidaridad, ciudadanía y justicia. Fue firmada conjuntamente por los presidentes de la Comisión, Consejo y Parlamento Europeo y proclamada de forma solemne el 7 de diciembre de 2000, con ocasión del Consejo Europeo de Niza.
} 
con un nombre de dominio propio ${ }^{42}$, aunque de momento se desconoce el mismo, ya que el Reglamento guarda silencio al respecto, por lo que probablemente sea objeto de una posterior determinación.

Este sitio de internet presenta carácter interactivo, esto es, no solo incluye contenido sino que está orientado a permitir el intercambio de información y con ello la tramitación del procedimiento de resolución de los litigios. Se garantiza, asimismo, la gratuidad de acceso electrónico por cualquier persona (incluidos los usuarios vulnerables) en todas las lenguas oficiales de las instituciones de la Unión, velándose por el respeto a la intimidad de sus usuarios ${ }^{43}$.

En aras a facilitar el acceso a la plataforma, están previstos los correspondientes enlaces desde las propias páginas web de la Comisión y, particularmente, a través del portal "Tu Europa» ${ }^{44}$, que contiene información sobre derechos y consejos prácticos dirigidos a los ciudadanos de la Unión Europea para vivir en cualquier lugar de la misma, con un apartado específico dedicado a los «consumidores».

Desde el punto de vista práctico, la plataforma de resolución de litigios en línea constituye una "ventanilla única» ${ }^{45}$ para los consumidores y comerciantes que deseen resolver extrajudicialmente los litigios incluidos en el ámbito de aplicación del Reglamento. A tal efecto, presenta una doble funcionalidad: cumple con el cometido principal de posibilitar la tramitación on line del asunto, pero además tiene un complementario carácter informativo.

42 En este sentido, Carlos JIMÉNEZ, «Sitio de internet en el centro de la estrategia digital», disponible en http://tendenciasdigitales.com/1032/sitio-de-internet-en-el-centro-de-la-estrategia-digital (consultado por última vez el 16 de abril de 2015).

El tratamiento de la información está sujeto a estrictas garantías de confidencialidad y se ajusta a las normas de protección de datos personales establecidas por la Directiva 95/46/CE del Parlamento Europeo y del Consejo, de 24 de octubre de 1995 (DOCE de 23 de noviembre de 1995, núm. L 281, pp. 31-50), y el Reglamento (CE) núm. 45/2001 del Parlamento Europeo y del Consejo, de 18 de diciembre de 2000 (DOCE de 12 de enero de 2001, núm. L 8, pp. 1-22). Véanse arts. 11, 12 y 13 del Reglamento. http://europa.eu/youreurope/index.htm

45 Sin perjuicio de la naturaleza pública o privada que puedan tener las distintas entidades de ADR autorizadas a resolver conflictos en el ámbito de consumo, la apuesta de la Unión Europea por una plataforma ODR pública («ventanilla única»), gestionada por la Comisión Europea, resulta un gran acierto a juicio de RICHARD GONZÁLEZ, para quien la citada plataforma podría equipararse a un juzgado en el sentido más físico y material del término, como lugar —en este caso virtualdonde se desarrollan los actos propios de la resolución del conflicto. Véase Manuel RICHARD GONZÁLEZ, «Los procedimientos electrónicos de resolución alternativa de conflictos (on-line dispute resolution)», op. cit., esp. p. 7. 
Por lo que respecta a este segundo aspecto, está previsto que la plataforma ponga a disposición pública información general sobre cuestiones tales como: la resolución extrajudicial de litigios como medio alternativo de solución de conflictos, la lista actualizada de entidades de resolución alternativa, un manual de presentación de reclamaciones, los puntos de contacto nacionales y datos estadísticos acerca de los resultados obtenidos de su utilización ${ }^{46}$.

En lo concerniente a la tramitación en línea del asunto, sin perjuicio de una atención más específica cuando examinemos el procedimiento ${ }^{47}$, la plataforma desempeña las siguientes funciones principales: facilita un formulario electrónico de reclamación, informa de la reclamación a la parte reclamada y se la transmite a la entidad de resolución alternativa ${ }^{48}$, ofreciendo gratuitamente un sistema electrónico de tramitación de asuntos con traducción incorporada cuando resulte necesario ${ }^{49}$.

Finalmente, proporciona un sistema de comentarios que permite a las partes expresar su opinión sobre el funcionamiento de la plataforma de resolución de litigios en línea y sobre la entidad de resolución alternativa de litigios que haya conocido de su litigio ${ }^{50}$.

Con un año de antelación a su definitiva puesta en marcha — fijada para el 9 de enero de 2016-, se encuentra previsto un ensayo ${ }^{51}$ de la funcionalidad técnica y facilidad de utilización por el usuario de la plataforma de resolución de litigios en línea, así como del formulario de reclamación, incluidos los as-

$46 \quad$ Art. 5.4 h) Reglamento ODR.

$47 \quad$ Véase infra aptdo. 5.

48 En este sentido, se propone un tipo de sistema «multipuertas» («the multi-door court house», en terminología inglesa) puesto que la plataforma recibe las reclamaciones y las deriva a una entidad de resolución de alternativa. La noción «multipuertas» surge como evolución de un centro de resolución de disputas en el cual un determinado conflicto ingresa y tras ser analizado por un operador de conflictos, este sugiere a las partes acudir a una de las múltiples posibilidades de abordaje que la situación de conflicto permitiría; modelo que terminó imponiéndose dentro de un importante sector del sistema de administración de justicia estadounidense. A este respecto, véase Óscar Daniel Franco CONFORTI, «Mediación electrónica (e-Mediación)», Diario La Ley, núm. 8519, 15 de abril de 2015, pp. $1-15$, esp. p. 5.

49 Art. 5.4 a-e) Reglamento ODR.

50 Art. 5.4 g) Reglamento ODR. La posibilidad de manifestar la opinión de las partes se encuentra abierta desde el momento de la conclusión del procedimiento y durante los seis meses siguientes, según el art. 8 Reglamento de ejecución (UE) 2015/1051, de la Comisión.

51 Art. 6 Reglamento ODR. 
pectos relativos a la traducción. La evaluación del citado ensayo por expertos ha de servir para resolver - con carácter previo- los problemas que puedan haber sido detectados en el correspondiente informe que la Comisión presentará al Parlamento Europeo y al Consejo sobre su resultado.

\section{IV. ÁMBITO DE APLICACIÓN}

La plataforma europea responde al objetivo de facilitar la resolución de litigios entre consumidores y comerciantes, aunque su ámbito de aplicación viene limitado por factores no solo de índole material sino también de carácter subjetivo y formal, como resulta de una interpretación conjunta del Reglamento ODR y la Directiva ADR, fundamentalmente del art. 2 de ambos textos legales.

En primer lugar, desde un punto de vista formal, la plataforma solo sirve para los procedimientos extrajudiciales de resolución de litigios ${ }^{52}$, quedando pues excluida su utilización para la tramitación de conflictos por juzgados y tribunales a través de los tradicionales cauces jurisdiccionales.

Así, resulta de general aplicación a los procedimientos de $\mathrm{ADR}^{53}$, sin distinción entre aquellos que finalizan con una solución impuesta o acordada, puesto que la plataforma ofrece cobertura tanto a los que sirven para imponer una solución (arbitraje) como a aquellos otros orientados a proponer o simplemente reunir a los interesados con el fin de facilitar una solución amistosa (mediación, conciliación) $)^{54}$.

Quedan exceptuados, sin embargo, ciertos supuestos en virtud de sus singulares características ${ }^{55}$, a saber: procedimientos asignados a personas físicas empleadas o retribuidas exclusivamente por el comerciante ${ }^{56} \mathrm{o}$ ante sistemas de tramitación de reclamaciones de los consumidores gestionados por el

\footnotetext{
52 Art. 2.1 Reglamento ODR.

53 Art. 2.1 Directiva ADR.

54 En el mismo sentido, Diana MARCOS FRANCISCO, "Las Online Dispute Resolution en materia de consumo en la Unión Europea», en Eduardo VÁZQUEZ CASTRO (dir.) y Carmen FERNÁNDEZ CANALES (coord.), Estudios sobre justicia online, Comares, Granada, 2013, pp. 23-42, esp. pp. 27 y 28. Art. 2.2 a), b), d), e) Directiva ADR.

56 En este caso se faculta, no obstante, a los Estados miembros a incluirlos dentro del ámbito de aplicación de la Directiva 2013/11/UE en sus normas de transposición estatales, ya que pueden constituir un medio eficaz de resolución temprana de litigios; siempre que se respeten el resto de requisitos exigibles a las entidades de resolución alternativa de litigios, especialmente la independencia y transparencia, que serán periódicamente evaluados (art. 2.2.a Directiva ADR).
} 
propio comerciante; los intentos realizados por un juez en el marco de un procedimiento judicial relativo a ese litigio y, por último, la negociación directa entre el consumidor y el comerciante, al considerarse previa al planteamiento del litigio ante una entidad de resolución alternativa.

En segundo lugar, por razón de la materia, a través de la plataforma se resuelve exclusivamente la conflictividad típica de las relaciones de consumo ${ }^{57}$, esto es, litigios relativos a obligaciones contractuales derivadas de contratos de compraventa o de prestación de servicios, mediante los cuales el consumidor adquiere a cambio de un precio la propiedad de ciertos bienes o el disfrute de servicios, transferidos o prestados respectivamente por un comerciante ${ }^{58}$. Únicamente se excluyen los litigios derivados de la prestación de servicios de atención sanitaria y de enseñanza pública complementaria o superior ${ }^{59}$.

Resulta obligado, además, que el contrato entre consumidor y usuario se haya celebrado en línea ${ }^{60}$, quedando excluidos de la utilización de la plataforma los litigios derivados de tradicionales relaciones de consumo, ofrecidas por el comerciante y encargadas por el consumidor fuera de Internet o sin utilizar otros medios electrónicos.

Si se produce tal circunstancia, el procedimiento podría ventilarse a través de la plataforma.

En España, parece que la posibilidad de que existan entidades en las que las personas decisoras estén empleadas o sean retribuidas exclusivamente por el empresario reclamado va a resultar admitida (art. 17.4 Anteproyecto Ley RACC), aunque de una manera excepcional para sectores en los que exista un alto nivel de conflictividad y escasa adhesión empresarial a estas entidades, y con la condición de que solo puedan adoptar una decisión vinculante para el empresario. Conocida como tipología B2C (Business to Consumers) ya que surge entre empresas y consumidores, para distinguirla de otras clases de ADR/ODR atendiendo a los sujetos en disputa, como son: $\mathrm{B} 2 \mathrm{~B}$ (Business to Business), $\mathrm{A} 2 \mathrm{C}$ (Administration to Consumers), $\mathrm{A} 2 \mathrm{~B}$ (Administration to Business), $\mathrm{A} 2 \mathrm{~A}$ (Administration to Administration) e inclusive person to person. Sobre los métodos ODR para las controversias B2C puede verse, más ampliamente, Pablo CORTÉS, «Un modelo para la acreditación de los sistemas ODR en la Unión Europea», en Justicia relacional y métodos electrónicos de resolución (ODR): hacia una armonización técnica y legal [monográfico en línea]. IDP. Revista de Internet, Derecho y Política, núm. 10, 2010, pp. 4-14, esp. pp. 6-8, disponible en la dirección: http://idp.uoc.edu/ojs/index.php/ $\mathrm{idp} /$ article/view/n10-cortes/n10-cortes (consultado por última vez el 28 de julio de 2014) Art. 4 b), c) Directiva ADR.

59 Art. 2.2 h), i) Directiva ADR.

60 Art. 2.1 Reglamento ODR. 
En efecto, el ámbito de aplicación del Reglamento ODR no se extiende a los litigios derivados de relaciones de consumo concertadas de manera tradicional $^{61}$, a los que - por el contrario- sí alcanza la Directiva $\mathrm{ADR}^{62}$.

Esta falta de coincidencia desemboca en la indeseada consecuencia de utilización de diferentes procedimientos para resolver los litigios de consumo, según estos provengan del e-commerce o, por el contrario, se hayan concertado personalmente. Para los primeros, las entidades de resolución alternativa cuentan con la plataforma, de la cual se ven privados para los segundos, que tendrán que resolver por otras vías.

A nuestro juicio, esta disparidad de régimen resulta criticable por innecesaria, ya que disponiendo del instrumento tecnológico representado por la plataforma, no hay razón aparente para excluir de su uso la litigiosidad derivada del comercio tradicional, so pena de incurrir en un agravio comparativo frente al comercio electrónico, dotando a este de un mayor nivel de protección ${ }^{63}$.

En tercer y último lugar, desde el punto de vista subjetivo, la plataforma se encuentra a disposición exclusiva de las entidades de resolución alternativa incluidas en la lista elaborada con arreglo al art. 20.2 Directiva ADR, esto es, que hayan superado los requisitos previstos en la misma, extensivos no solo a la propia entidad, sino también a las personas encargadas de solucionar el litigio y a los procedimientos utilizados ${ }^{64}$.

61 Aspecto criticado también por VILALTA NICUESA, quien constata que la plataforma no aborda todos los supuestos que pueden originarse en el tráfico económico, porque el ámbito de aplicación del Reglamento es limitado y mantiene al margen los conflictos derivados de las transacciones offline. Véase Aura Esther VILALTA NICUESA, «La paradoja de la mediación en línea. Recientes iniciativas de la Unión Europea y de la CNUDMI», op. cit., esp. p. 32.

62 Art. 2.1 Directiva ADR.

63 En este sentido, también, Inmaculada BARRAL VIÑALS, «Reclamaciones de consumo y ODR: procesos automáticos, small claims y plataformas interactivas», Revista Aranzadi de Derecho y nuevas tecnologías, núm. 34, enero-abril 2014, pp. 43-65, esp. pp. 46-47, para quien la resolución electrónica de conflictos no es una categoría únicamente vinculada a los conflictos nacidos de transacciones en red: puede utilizarse para cualquier tipo de conflicto y ello le añade más versatilidad. Los procesos electrónicos de resolución de conflictos pueden generalizarse a cualquier tipo de conflicto, esté o no vinculado al comercio electrónico, pasando a ser un nuevo canal de reclamaciones puesto a disposición del ciudadano, por su rapidez y bajo coste. Más ampliamente, véase nuestro trabajo: Félix VALBUENA GONZÁLEZ, «La directiva europea sobre resolución alternativa de litigios (ADR) en materia de consumo", op. cit., esp. pp. 435-441. 
Así pues, la resolución en línea de un litigio a través de la plataforma exige, en todo caso, la intervención de una entidad de resolución alternativa, que — sin embargo — no se encuentra obligada a utilizar su sistema de tramitación de asuntos, pudiendo servirse para este fin de sus propios medios (página web institucional), siempre que no impliquen la comparecencia personal de las partes, de cara a mantener su condición procedimental de ODR ${ }^{65}$.

En cuanto a las partes, la plataforma admite una posible bidireccionalidad del litigio ${ }^{66}$, esto es, que sea planteado no solo por el consumidor frente al comerciante sino también por este contra aquel ${ }^{67}$, condicionada a que la legislación del Estado miembro de residencia habitual del consumidor prevea que tales litigios puedan resolverse con la intervención de una entidad de resolución alternativa.

Resulta, por último, indiferente que el litigio presente carácter transfronterizo o nacional, esto es, que el consumidor al realizar la orden de pedido tenga su residencia en otro o en el mismo Estado en el que se encuentra establecido el comerciante, siempre que los Estados de residencia y establecimiento respectivamente se hallen dentro del ámbito de la Unión Europea ${ }^{68}$.

65 En opinión de VILALTA NICUESA, son muchas las ventajas cuantitativas y cualitativas que acompañan las modalidades electrónicas de gestión y resolución de las controversias. La tecnología y sus aplicaciones han logrado superar las barreras de tiempo, distancia y lenguajes que hasta ahora habían devenido obstáculos insalvables para la universalización de la justicia en los ámbitos de las controversias transnacionales y de los consumidores. Véase Aura Esther VILALTA NICUESA, «Resolución electrónica de disputas. Primeras reflexiones en torno a la necesidad de un marco normativo internacional», en Justicia relacional y métodos electrónicos de resolución $(O D R)$ : hacia una armonización técnica y legal [monográfico en línea]. IDP. Revista de Internet, Derecho y Política, núm. 10, 2010, pp. 15-23, esp. p. 16, disponible en la dirección: http://idp.uoc.edu/ojs/index.php/idp/article/view/ n10-vilalta/n10-vilalta (consultado por última vez el 28 de julio de 2014).

66 Art. 2.2 Reglamento ODR.

67 Esta circunstancia distingue también el ámbito de aplicación del Reglamento ODR y de la Directiva ADR, pues esta última no se aplica —en ningún caso- a los procedimientos iniciados por un comerciante contra un consumidor (art. $2.2 \mathrm{~g}$ ) Directiva ADR). En este sentido, también, Aura Esther VILALTA NICUESA, «La paradoja de la mediación en línea. Recientes iniciativas de la Unión Europea y de la CNUDMI", op. cit., esp. 17, para quien resulta paradójica esta falta de coincidencia, poniendo de relieve que los comerciantes pueden elevar reclamaciones frente a los consumidores a través de la plataforma, pero a su vez el Reglamento no impone a los Estados miembros la obligación de garantizar que las entidades de resolución alternativa ofrezcan procedimientos en línea.

Art. 2.1 Reglamento ODR, en relación con art. 4 e) y d) Directiva ADR. 


\section{TRAMITACIÓN EN LÍNEA DEL PROCEDIMIENTO}

Como anticipamos ${ }^{69}$, al margen de su función informativa, la mayor virtud de la plataforma reside en ofrecer gratuitamente a los interesados un sistema de tramitación para resolver el litigio derivado de una relación de consumo concertada en línea.

La característica fundamental de este procedimiento reside en que también se produce on line, es decir, sin la comparecencia personal de las partes o de sus representantes ante la entidad de resolución alternativa ${ }^{70}$. La presencia de los interesados se faculta solo en el supuesto de que las normas de procedimiento de la entidad correspondiente contemplen tal posibilidad y las partes presten su consentimiento.

De esta forma, el procedimiento se inicia con la presentación y admisión de la reclamación, continúa con el traslado a la parte contraria y determinación de la entidad de resolución alternativa competente, finalizando con la resolución del litigio ${ }^{71}$; fases que seguidamente examinamos.

\section{PRESENTACIÓN DE LA RECLAMACIÓN}

La cumplimentación de un formulario electrónico a instancia de parte interesada constituye la forma prevista para presentar una reclamación ante la plataforma de resolución de litigios. Admitida la posible bidireccionalidad del litigio $^{72}$, la legitimación activa corresponde no solo a los consumidores sino también a los comerciantes, aunque lo más habitual será la presentación a instancia de los primeros, que tradicionalmente ostentan la posición débil en las relaciones de consumo.

Los modelos de formulario no están todavía elaborados, precisando de los correspondientes actos delegados y de ejecución por parte de la Comisión para adaptar la información relacionada en el Anexo del Reglamento, comprensiva de los datos a suministrar por el reclamante, que sí están definidos ${ }^{73}$.

$69 \quad$ Véase supra apdo. III.2.

70 Art. 10 b Reglamento ODR.

71 En opinión de Inmaculada BARRAL VIÑALS, «Reclamaciones de consumo y ODR: procesos automáticos, small claims y plataformas interactivas», op. cit., esp. pp. $64 \mathrm{y}$ 65, estamos claramente ante un supuesto de «case resolution», ya que se trata de la creación de una plataforma que incorpora directamente técnicas de resolución de conflictos, superando lo que se conoce como «case management», que supondría únicamente encauzar la reclamación del consumidor a la entidad competente para resolverla.

72 Véase supra apdo. IV.

73 La información que deberá suministrarse al presentar una reclamación se ajusta a la siguiente: 1) Indicación de si la parte reclamante es un consumidor o un comer- 
En cualquier caso, el formulario deberá ser de fácil acceso y utilización por el usuario y la información contenida suficiente para determinar la entidad de resolución alternativa competente ${ }^{74}$.

Para facilitar su cumplimentación, el impreso electrónico de reclamación será accesible en todas las lenguas oficiales de las instituciones de la Unión, pudiendo guardarse y modificarse como borrador antes de su presentación. Si finalmente no se cumplimenta íntegramente o no se presenta, se elimina automáticamente de la plataforma seis meses después de su creación ${ }^{75}$.

$\mathrm{El}$ antecedente inmediato de este formulario electrónico viene constituido por el denominado «European consumer complaint form» (formulario europeo de reclamación para el consumidor), recogido en la Comunicación que acompaña a la Recomendación 1998/257/CE, de 30 de marzo, relativa a los principios aplicables a los órganos responsables de la solución extrajudicial de litigios en materia de consumo ${ }^{76}$.

Este impreso tipo, también disponible en todas las lenguas oficiales de la $\mathrm{UE}^{77}$, fue concebido para orientar al consumidor en la formulación de la reclamación y alcanzar un acuerdo con el profesional, resultando de especial

ciante; 2) Nombre y dirección de correo electrónico y ordinario del consumidor; 3) Nombre y dirección de correo electrónico y ordinario del comerciante; 4) Nombre y dirección de correo electrónico y ordinario del representante de la parte reclamante, si procede; 5) Idioma o idiomas de la parte reclamante, si procede; 6) Idioma de la parte reclamada, si se conoce; 7) Tipo de mercancía o de servicio a que se refiere la reclamación; 8) Indicación de si la mercancía o el servicio fue ofrecido por el comerciante y encargado por el consumidor a través de un sitio de internet o por otros medios electrónicos; 9) Precio de la mercancía o del servicio adquirido; 10) Fecha en que el consumidor adquirió la mercancía o el servicio; 11) Indicación de si el consumidor ha entablado contacto directo con el comerciante; 12) Indicación de si el litigio está siendo o ha sido previamente examinado por una entidad de resolución alternativa o por un órgano jurisdiccional; 13) Tipo de reclamación; 14) Descripción de la reclamación; 15) En caso de que la parte reclamante sea un consumidor, indicación de la entidad o las entidades de resolución alternativa que el comerciante esté obligado o se haya comprometido a utilizar con arreglo al art. 13, apartado 1, de la Directiva 2013/11/UE, si se conocen; 16) En caso de que la parte reclamante sea un comerciante, indicación de la entidad o de las entidades de resolución alternativa que este se haya comprometido o esté obligado a utilizar.

74 Art. 8 Reglamento ODR.

75 Art. 2 Reglamento de ejecución (UE) 2015/1051, de la Comisión.

76 Véase supra apdo. II.

77 A través del enlace contenido en la siguiente dirección electrónica: http://ec.europa.eu/consumers/solving_consumer_disputes/non-judicial_redress/ecc-net/index_en.htm (consultado por última vez el 19 de mayo de 2015). 
utilidad en el supuesto de litigios transfronterizos ${ }^{78}$. La combinación de un sistema de opciones múltiples y de texto libre facilita considerablemente la traducción en este tipo de asuntos, en que los interesados pueden expresarse en idiomas distintos.

Volviendo al formulario electrónico, el mismo tiene prevista la funcionalidad de adjuntar archivos, mediante los cuales la parte reclamante puede acompañar documentos en apoyo de su pretensión. La aportación de documentos in limine litis nos parece adecuada, en aras de un elemental principio de economía procesal, evitando así el inconveniente de tener que aportarlos en un momento posterior.

Los documentos más habituales en este tipo de reclamaciones serán aquellos que resulten acreditativos de la contratación, pago y, en su caso, defecto en la entrega de la cosa o prestación del servicio. Al tratarse de comercio en línea, los documentos constarán normalmente en archivos digitales, lo que facilita su aportación; en caso contrario, cuando el documento conste en papel, será necesario proceder a su escaneo antes de adjuntarlo a la reclamación electrónica.

Presentada la reclamación acompañada de los documentos, procede su tramitación, salvo que alguna de las secciones del formulario no haya sido cumplimentada $^{79}$, lo que se considera un defecto subsanable. En este caso, se informa de que la reclamación no puede seguir tramitándose a no ser que se facilite la información que falta ${ }^{80}$.

Entendemos que tanto la admisión a trámite como la necesidad de subsanación de defectos se realizan sin intervención humana, esto es, son funcionalidades incorporadas a la plataforma, de manera que la cumplimentación íntegra del formulario conduce automáticamente a tramitar la reclamación.

\section{DETERMINACIÓN DE LA ENTIDAD DE RESOLUCIÓN COMPETENTE}

Presentada en forma la reclamación, la siguiente fase de la tramitación en línea consiste en determinar la entidad de resolución alternativa competente para resolver el litigio, que se intenta mediante un intercambio de información entre los interesados. Así, en primer lugar, la plataforma transmite el

78 Una amplia perspectiva de la problemática que generan los litigios transfronterizos se aborda en el estudio: Francisco RAMOS MÉNDEZ, Arbitraje y litigios transfronterizos en un foro global, Atelier, Barcelona, 2005; también puede verse José Alberto REVILLA GONZÁLEZ, «Los métodos alternativos de resolución de conflictos en materia de consumo. Las relaciones transfronterizas», Estudios sobre Consumo, núm. extraordinario, diciembre 2006, pp. 59-74, esp. pp. 67-74.

79 Art. 9.1 Reglamento ODR.

80 Art. 9.2 Reglamento ODR. 
formulario a la parte reclamada ${ }^{81} \mathrm{y}$, posteriormente, comunica la contestación de esta a la parte reclamante ${ }^{82}$.

A tales efectos, la plataforma está provista de un sistema de traducción que debe permitir la transmisión en una lengua oficial de las instituciones de la Unión Europea comprensible para el receptor de la información. El buen funcionamiento de esta herramienta se nos antoja imprescindible para una comunicación adecuada entre partes que se expresan en distintos idiomas, como sucede habitualmente en los litigios transfronterizos.

La determinación de la entidad competente aparece como requisito sine qua non para la tramitación del asunto, de suerte que si no se alcanza un acuerdo entre los interesados o no se identifica ninguna entidad, la reclamación no podrá seguir tramitándose ${ }^{83}$, lo que se compadece bien con la voluntariedad característica de los sistemas ODR.

En efecto, la obligación de sometimiento a una entidad de resolución alternativa privaría a los interesados del derecho a la tutela judicial efectiva por parte de juzgados y tribunales, garantizado en el art. 47 de la Carta de los Derechos Fundamentales de la Unión Europea.

La determinación, en concreto, de la entidad de resolución competente depende, en primer lugar, de la condición de la parte reclamada. Si se trata de un consumidor, este cuenta con un plazo de 10 días naturales desde la recepción del formulario, para aceptar la entidad a la que esté obligado a recurrir el comerciante ${ }^{84} \mathrm{o}$, en caso contrario, para seleccionar una entre las mencionadas en el formulario o determinadas por la plataforma basándose en la información contenida en aquel ${ }^{85}$.

En este último caso, la plataforma ofrece una lista indicativa de entidades basándose en dos criterios: de un lado, las direcciones geográficas de las partes indicadas en el impreso electrónico y, de otro lado, el sector a que el litigio se refiere; todo ello, sin perjuicio de la garantía de acceso a la lista íntegra de

81 A través de un mensaje electrónico normalizado a la dirección electrónica de la parte reclamada indicada por el reclamante en el impreso electrónico de reclamación, según el art. 3 Reglamento de ejecución (UE) 2015/1051, de la Comisión. Art. 9.3 y 9.4 Reglamento ODR, respectivamente.

83 Art. 9.3 a) Reglamento ODR.

84 Recordemos, a este respecto, que el art. 13.1 de la Directiva 2013/11/UE impone a los Estados miembros la obligación de velar por que los comerciantes establecidos en sus territorios informen a los consumidores acerca de la entidad o entidades de resolución alternativa —incluyendo su dirección web— que den cobertura a dichos comerciantes, cuando estos se comprometan o estén obligados a recurrir a las mismas para resolver litigios con los consumidores. Art. 9.3 d) Reglamento ODR. 
las entidades registradas, contando además las partes con una herramienta de búsqueda para su selección, proporcionada por la plataforma ${ }^{86}$.

$\mathrm{Si}$, por el contrario, la parte reclamada es un comerciante, podemos encontrarnos ante dos situaciones:

De un lado, que el reclamante conozca la entidad de resolución a la que está obligado a recurrir el comerciante y lo haya hecho constar en el formulario o bien la plataforma la determine basándose en la información facilitada en el formulario ${ }^{87}$, en cuyo caso la competencia se determina automáticamente ${ }^{88}$.

De otro lado, que el reclamante desconozca tal información, en cuyo caso se requiere al comerciante para que en el plazo de diez días declare si se compromete o está obligado a recurrir a una determinada entidad o, en caso contrario, estaría dispuesto a someterse a cualquiera de las mencionadas por el reclamante o determinadas por la plataforma basándose en la información facilitada en el formulario ${ }^{89}$.

Así pues, salvo en el caso de que el comerciante se haya visto obligado a recurrir previamente a una entidad de resolución alternativa para resolver los litigios planteados por sus clientes, debemos entender que en el resto de supuestos la falta de aceptación de la parte reclamada - consumidor o comercianteacerca de la entidad competente impide la continuación del procedimiento en línea.

En aras del principio de celeridad, también se pone fin a la tramitación por el mero transcurso de 30 días naturales desde la presentación del formulario de reclamación sin que las partes hubieran llegado a un acuerdo sobre una entidad de resolución alternativa ${ }^{90}$. Por el contrario, mediando un acuerdo, la plataforma de resolución de litigios transmite —automáticamente y sin demora- la reclamación a la entidad de resolución alternativa a la que las partes hayan acordado someter el litigio ${ }^{91}$.

\footnotetext{
86 Art. 4 Reglamento de ejecución (UE) 2015/1051, de la Comisión.

87 Art. 9.3 b) Reglamento ODR.

88 En este sentido, también, Diana MARCOS FRANCISCO, "Las Online Dispute Resolution en materia de consumo en la Unión Europea», op. cit., esp. p. 41, para quien si el reclamante es un comerciante obligado a recurrir a determinada entidad de ADR y el consumidor acepta la misma tras el requerimiento efectuado al efecto por un plazo de 10 días, no procederá este nuevo traslado virtual, pues la plataforma remitirá automáticamente y sin demora la reclamación a la repetida entidad. Art. 9.3 c) Reglamento ODR.

Art. 9.8 Reglamento ODR.

Art. 9.6 Reglamento ODR.
} 
Finalmente, se abre un trámite de aceptación por parte de la entidad de resolución alternativa, que tiene la posibilidad de rechazar el asunto, solo por causas tasadas y mediante resolución motivada, según establece el art. 5 de la Directiva ADR.

Los motivos de rechazo se encuentran limitados a supuestos relacionados con: a) falta de negociación previa; b) litigio frívolo o vejatorio; c) litispendencia o cosa juzgada; d) cuantía por debajo de un umbral monetario preestablecido $^{92}$; e) prescripción de la acción por transcurso de un plazo mínimo de un año; y, como cláusula residual: f) el hecho de que la tramitación del litigio pudiera comprometer gravemente por otros motivos el funcionamiento de la entidad de resolución alternativa.

La resolución de inadmisión deberá incluir una exposición razonada de los motivos por los que no se ha tramitado el litigio y dictarse en plazo no superior a tres semanas, desde la recepción del expediente ${ }^{93}$. Por el contrario, en caso de aceptación del litigio, la entidad de resolución se lo comunica a las partes, informándoles asimismo sobre sus normas de procedimiento y, en su caso, las costas del procedimiento ${ }^{94}$.

En definitiva, existen tres supuestos ${ }^{95}$ que pueden acontecer sucesivamente en el tiempo, impeditivos de la tramitación del litigio presentado a través de la plataforma: de un lado, que la parte reclamada afirme no estar dispuesta a someterse a una entidad de resolución alternativa; de otro lado, que las partes no consigan en 30 días desde la presentación de la reclamación ponerse de acuerdo sobre dicha entidad y, finalmente, que esta rehúse tramitar el litigio.

\section{RESOLUCIÓN DEL LITIGIO}

La entidad que acepta tramitar una reclamación adquiere sendos compromisos: uno principal, de concluir el procedimiento en el plazo de no-

92 Esta causa de inadmisión resulta criticable si el umbral monetario preestablecido se encuentra por encima de una cantidad de dinero relevante. Recordemos que las reclamaciones en materia de consumo se caracterizan —en muchas ocasiones_ por su escasa cuantía, de manera que resulta inapropiado establecer un límite mínimo, que impida el acceso al procedimiento de la pequeña litigiosidad. Somos partidarios, por tanto, de la admisión de cualquier reclamación con independencia de su cuantía económica, para ofrecer —así — una cobertura absoluta a la resolución de los conflictos derivados de relaciones de consumo. En España, la previsión es que pueda inadmitirse una reclamación en el supuesto que el valor de la pretensión ejercitada fuera inferior a 50 euros o superior a 3.000 euros (15.1 e) Anteproyecto Ley RACC).

93 Art. 5.4 Directiva ADR.

94 Art. 9.7 Reglamento ODR.

95 Art. 6.1 Reglamento de ejecución (UE) 2015/1051 de la Comisión. 
venta días naturales ${ }^{96}$, y otro accesorio, de transmitir seguidamente y sin demora a la plataforma información relativa a los siguientes aspectos: fechas de recepción del expediente y conclusión del procedimiento, objeto del litigio y resultado ${ }^{97}$.

Curiosamente, la entidad no está sujeta a tramitar el procedimiento a través de la plataforma de resolución de litigios en línea ${ }^{98}$, si bien para mantener su carácter on line no puede exigir la comparecencia de las partes o de sus representantes ${ }^{99}$, a no ser que las normas de procedimiento contemplen esa posibilidad y las partes lo consientan ${ }^{100}$.

Esta aparente contradicción conduce a concluir que, una vez aceptada la reclamación, la entidad puede utilizar su propio sitio de Internet - necesariamente provisto de esta funcionalidad, conforme al art.5.2 Directiva ADRpara tramitar y concluir el procedimiento.

En efecto, entre las condiciones exigidas a las entidades de resolución alternativa figura la de contar con un sitio de Internet propio y actualizado, de cara a facilitar el acceso a las mismas - ante el fundado temor de desconocimiento por parte de consumidores y comerciantes de las vías extrajudiciales de solución de conflictos-, así como garantizar su transparencia.

La citada web institucional, al margen de ofrecer la oportuna información acerca de la entidad, ha de permitir la tramitación del procedimiento en línea, esto es, la presentación de la reclamación e intercambio de información entre las partes por vía electrónica.

Sin embargo, a priori, nos parece preferible la utilización íntegra de la plataforma de resolución de litigios en línea, que ofrece gratuitamente ${ }^{101}$ un sistema electrónico de tramitación de asuntos, sin necesidad de escindir el procedimiento en dos partes en distintos sistemas: alegaciones de los interesa-

96 Art. 8 d) Directiva ADR. El dies a quo del cómputo de este plazo de 90 días naturales coincide con la fecha de recepción por la entidad de resolución alternativa del expediente completo de la reclamación, según establece el art. 5.2 del Reglamento de ejecución (UE) 2015/1051, de la Comisión.

97 Art. 10 c) Reglamento ODR.

98 Art. 10 d) Reglamento ODR.

99 Art. 10 b) Reglamento ODR.

100 Véase, también, Aura Esther VILALTA NICUESA, «La paradoja de la mediación en línea. Recientes iniciativas de la Unión Europea y de la CNUDMI», op. cit., quien afirma que «en ningún caso estas entidades están obligadas a tramitar el procedimiento de resolución alternativa a través de la plataforma europea» (p. 18).

Art. 5.4 d) Reglamento ODR. 
dos y aceptación de la entidad, en la plataforma general ${ }^{102}$; resto del trámite y decisión, en la página web de la entidad.

Bien entendido que la entidad de resolución alternativa resolverá siempre el litigio aplicando sus propias reglas de procedimiento, regidas en todo caso por los principios de eficacia, igualdad, libertad y legalidad ${ }^{103}$.

Los dos últimos principios, característicos de los procedimientos que finalizan con una solución impuesta, implican — de un lado- el carácter no vinculante para el consumidor de los acuerdos de sometimiento previos al surgimiento del conflicto (principio de legalidad) ${ }^{104} \mathrm{y}$ - de otro lado- la aplicación en la decisión del derecho imperativo del Estado miembro donde tenga su residencia el consumidor, exista o no, conflicto de Leyes (principio de legalidad).

Una vez definida la entidad de resolución competente, el Reglamento no incluye disposiciones relativas a la tramitación de asuntos ${ }^{105}$, obligando exclusivamente al cumplimiento del plazo ( 90 días para la resolución de la controversia) ${ }^{106}$ y rendición de cuentas a la plataforma (información sobre resultado del procedimiento).

Si no se explota toda la potencialidad que ofrece la plataforma europea de resolución de litigios en línea, se corre el riesgo cierto de convertirla en un

102 En este caso, la misión encomendada a la plataforma se reduciría a «un servicio de gestión previa del expediente», como acertadamente se pone de relieve en: Aura Esther VILALTA NICUESA, «La paradoja de la mediación en línea. Recientes iniciativas de la Unión Europea y de la CNUDMI», op. cit., esp. p. 32.

103 Arts. 8, 9, 10 y 11 Directiva ADR.

104 Este principio, íntimamente relacionado con la garantía del derecho a la tutela judicial efectiva, posibilita que el consumidor acuda -en todo caso- a los órganos jurisdiccionales para la solución del conflicto. Ya ha sido incorporado al Derecho español en el art. 57.4 LGDCU por la Ley 3/2014, de 27 de marzo, que extiende al Sistema Arbitral de Consumo la no validez del compromiso arbitral del consumidor, previo a la disputa, que hasta entonces se consideraba válido y vinculante.

105 En este sentido, Manuel RICHARD GONZÁLEZ, «Los procedimientos electrónicos de resolución alternativa de conflictos (on-line dispute resolution)», op. cit., esp. p. 13, quien constata cómo, en realidad, en el Reglamento se atiende más al sistema de plataforma electrónica que al procedimiento en sí, cuyo contenido se difiere a lo que pueda establecer la entidad de resolución de conflictos en el marco de lo previsto en la legislación que le resulte aplicable.

106 El Arbitraje de Consumo español debe adaptarse a esta obligación. A tal efecto, la Disposición final quinta del Anteproyecto Ley RACC prevé la modificación del art. 49.1 del Real Decreto 231/2008, de 15 de febrero, por el que se regula el Sistema Arbitral de Consumo, reduciendo a noventa días naturales el plazo para dictar el laudo, que ahora se encuentra fijado en seis meses. 
simple buzón de reclamaciones presentadas por los consumidores, eso sí, en formato electrónico.

\section{REFLEXIÓN FINAL}

La creación de una plataforma europea de resolución en línea de litigios —a través de la publicación del Reglamento (UE) núm. 524/2013 de 21 de mayo-, supone un nuevo avance en el fomento de vías alternativas de solución de conflictos en materia de consumo, centrado en este caso en los sistemas ODR (Online Dispute Resolution), que se caracterizan por su completa sustanciación en un entorno virtual electrónico, resultando innecesaria la presencia física de las partes o sus representantes en un lugar común.

Esta novedosa iniciativa, carente de precedentes en el ámbito europeo, resulta coetánea en el tiempo con la publicación de la primera lista de «entidades de resolución alternativa de litigios», que debe estar disponible antes del 9 de enero de 2016. Dicha denominación aparece reservada — conforme a lo dispuesto en la Directiva 2013/11/UE, de 21 de mayo- para aquellas que superan un sistema de evaluación acerca de los requisitos atinentes a la propia entidad, las personas encargadas de solucionar el litigio y los procedimientos utilizados.

En este aspecto, la plataforma se concibe como instrumento al servicio de las entidades de resolución alternativa, de tal forma que solo aquellas que hayan superado unos niveles de calidad armonizados en toda la Unión Europea podrán hacer uso de la plataforma para resolver litigios de consumo.

Desde el punto de vista cronológico, la trayectoria seguida hasta el momento de consolidar estructuras de ADR (Alternative Dispute Resolution) para la solución de los litigios de consumo antes de habilitar un sistema ODR mediante la creación de la plataforma europea nos parece acertada.

Son varias las instituciones que asumen algún tipo de responsabilidad en relación con la plataforma, asumiendo cada una diferentes cometidos. Así, en la tarea de sensibilización e información a los consumidores sobre su propia existencia se involucra, principalmente, a los Estados miembros, pero también a los propios comerciantes y a los denominados mercados en línea; sin embargo, la puesta en marcha y funcionamiento de la plataforma corresponde esencialmente a la Comisión, mientras que el apoyo en la tramitación de las reclamaciones recae sobre los puntos de contacto nacionales de litigios en línea.

Aunque la plataforma cumple con una labor general de carácter informativo acerca de los medios de resolución de litigios alternativos a la vía judicial en el ámbito de las relaciones de consumo, nos interesa sobre todo su función de posibilitar la tramitación on line del asunto cuando surja un determinado 
conflicto entre comerciante y consumidor con ocasión de la prestación de un servicio o adquisición de un producto.

En este sentido, el ámbito de aplicación de la plataforma se extiende a la solución extrajudicial de conflictos con la intervención de una entidad de resolución alternativa, entre consumidores residentes frente a comerciantes establecidos en la Unión Europea, derivados de relaciones de consumo concertadas en línea, salvo en las materias relativas a prestación de servicios de atención sanitaria y de enseñanza pública.

Desde nuestro punto de vista, la exclusión de los litigios derivados del consumo tradicional resulta innecesaria, ya que la plataforma puede constituir un instrumento útil para las entidades de resolución alternativa, que se ven privadas de su utilización para resolver ese tipo de controversias.

Apostamos, en definitiva, por hacer coincidir el ámbito de aplicación del Reglamento ODR con el propio de la Directiva ADR, que - por el contrario- sí alcanza al comercio tradicional.

En cuanto a la tramitación on line del procedimiento, destacan - sobre todo- dos funciones de la plataforma: de un lado, el formulario electrónico de reclamación y, de otro lado, el sistema integrado de traducción.

En efecto, de partida, la plataforma se presenta como «ventanilla única» para la presentación de reclamaciones en formulario electrónico, no solo por los consumidores sino también por los comerciantes, ya que se admite la bidireccionalidad del litigio. Después, proporciona a las partes y a la entidad de resolución alternativa la traducción de la información que sea necesaria y se intercambie a través de la plataforma.

Con el objetivo de facilitar la resolución del litigio, la plataforma ofrece finalmente un sistema electrónico gratuito de tramitación de asuntos, cuya utilización — curiosamente - resulta potestativa para las entidades de resolución alternativa, que pueden utilizar su propia web institucional, dotada de esta funcionalidad. Sin embargo, para no dividir la continencia de la causa, nos parece preferible utilizar íntegramente en estos casos la plataforma europea, máxime cuando a través de ella se ha presentado la reclamación en formulario electrónico y se ha determinado la entidad de resolución competente. 